TADRIS : JURNAL PENDIDIKAN ISLAM
http://ejournal.iainmadura.ac.id/index.php/tadris
E-ISSN : 2442-5494; P-ISSN: 1907-672X

\title{
Dari Surau ke Madrasah : Modernisasi Pendidikan Islam di Minangkabau 1900-1930 M
}

\author{
Rengga Satria \\ Universitas Negeri Padang \\ renggasatria@fis.unp.ac.id
}

\begin{abstract}
Keywords:

Surau;

This study concludes that the modernization movement of

Madrasah; Islamic education that occurred in Minangkabau in the period Minangkabau. 1900-1930 caused the "disappearance" of its function as a traditional Islamic education institution in Minangkabau. Madrasa system then introduced by ulama kaum muda to replace surau as Islamic education institution. Through the madrasa system, ulama kaum muda have succeeded in dialogue the modernity with Islam. This research is a library research using qualitative methods with a socio-historical approach. Through this socio-historical approach, the author does not only want to present this research in a factual descriptive manner, but also tries to reveal facts through an analysis-critical perspective.
\end{abstract}

\section{Abstrak:}

Kata Kunci:

Surau; Penelitian ini menyimpulkan bahwa gerakan modernisasi

Madrasah; pendidikan Islam yang terjadi di Minangkabau pada periode

Minangkabau. 1900-1930 menyebabkan "musnah"nya fungsi surau sebagai lembaga pendidikan Islam tradisional di Minangkabau. Sistem Madrasah kemudian diperkenalkan oleh ulama kaum muda menggantikan surau sebagai lembaga pendidikan Islam. Melalui sistem madrasah, ulama kaum muda berhasil mendialogkan modernitas dengan Islam. Penelitian ini merupakan library research (penelitian kepustakaan) dengan menggunakan metode kualitatif dan pendekatan sosio-historis. Melalui pendekatan sosio-historis ini, penulis tidak hanya ingin menampilkan penelitian ini dengan deskriptif-faktual, namun juga berusaha mengungkapkan fakta melalui cara pandang analisis-kritis.

Received : 12 Oktober 2019; Revised: 12 Nopember 2019; Accepted: 10 Desember 2019 http://doi.org/10.19105/tjpi.

(C) Tadris Jurnal Pendidikan Islam

Institut Agama Islam Negeri Madura, Indonesia
This is an open access article under the CC-BYNC license 


\section{Pendahuluan}

Pada awal abad $20 \mathrm{M}$, seiring dengan munculnya gerakan modernisasi Islam di Timur Tengah yang berefek terhadap dinamika keagamaan di Nusantara, maka pendidikan Islam tradisional yang sudah ada sebelumnya mendapatkan tantangan yang luar biasa. ${ }^{1}$ Kondisi ini diperparah oleh kebijakan kolonial Belanda dengan politik etisnya. Sebagaimana dijelaskan oleh Herrera ${ }^{2}$ bahwa pendidikan barat yang diperkenalkan pada akhir abad $19 \mathrm{M}$ menyebabkan corak pendidikan Islam di seluruh dunia Islam mengalami perubahan. Lembaga pendidikan Islam tradisional "dipaksa" atau dalam bahasa Steenbrink disebut dengan "menolak sambil mencontoh" model pendidikan yang diperkenalkan oleh kaum pembaharu dan kolonial.

Gerakan modernisasi pendidikan Islam sangat terlihat dinamikanya di Minangkabau. Hal ini ditandai dengan keberadaan surau sebagai lembaga pendidikan Islam mulai dipertanyakan otoritasnya. Gesekan dengan gerakan modernisasi menyebabkan eksistensi surau sebagai lembaga pendidikan Islam di Minangkabau mengalami kemunduran yang sangat signifikan, bahkan Azra menyebutnya dengan kepunahan. ${ }^{3}$

\section{Metodologi Penelitian}

Penelitian ini merupakan library research (penelitian kepustakaan) dengan menggunakan metode kualitatif dan pendekatan sosio-historis.

Melalui pendekatan sosio-historis ini, penulis tidak hanya ingin menampilkan penelitian ini dengan deskriptif-faktual, namun juga berusaha mengungkapkan fakta melalui cara pandang analisis-kritis.

\section{Pembahasan}

A. Geneologi dan eksistensi surau sebagai Pendidikan Islam

Surau merupakan lembaga pendidikan Islam tradisional di Minangkabau yang tidak bisa dipisahkan dari sejarah Islamisasi kebudayaan Minangkabau itu sendiri. Sama halnya dengan pesantren di pulau Jawa, surau juga merupakan lembaga adat yang mengalami proses Islamisasi. Sebelum datangnya Islam, surau merupakan tempat penyembahan terhadap nenek moyang yang biasanya didirikan di daerah-daerah perbukitan atau tempat yang lebih tinggi dari lingkungannya.

Kata "surau" merupakan kata yang sudah banyak digunakan di Minangkabau, Sumatera Selatan, Semenanjung Malaysia, Sumatera Tengah dan Patani. Penggunaan lembaga surau di setiap wilayah Melayu-Indonesia ini memiliki kesamaan yaitu sebagai tempat penyembahan dan lembaga adat. ${ }^{4}$

Surau sebagai lembaga pendidikan Islam tradisional di Minangkabau pertama kali didirikan oleh Syaikh Burhanuddin (1066-1111 H/ 1646-1591 M) di Ulakan. Di surau inilah Syaikh Burhanuddin melakukan pengajaran Islam dan mendidik beberapa murid yang menjadi ulama yang berperan penting dalam

\footnotetext{
${ }^{1}$ Robert W Hefner (edit), The New Cambridge History of Islam, vol 6: Muslims and Modernity Culture and Society since 1800 (London: Cambridge University Press, 2011). ${ }_{2}$ Modernisasi pendidikan menjadi fenomena global sejak pertengahan abad ke 19 yang mempengaruhi masyarakat dunia terutama dunia Islam. Lihat, Linda Herrera, Education, Islam, and Modernity: Beyond Westernization and Centralization. Comparative Education Review, Vol. 48, No. 3 (August 2004), pp. 318-326. Accessed: 11/12/2013 21:59

$278 \quad{ }^{3}$ Azyumardi Azra, Surau: Pendidikan Islam Tradisional dalam Transisi dan Modernisasi ( Ciputat: Logos, 2003).

4 Hasan Madmarn, The Pondok and Madrasah in Patani (Bangi: Penerbit Universiti

Kebangsaan Malaysia, 1999)
} 
pengembangan ajaran Islam di Minangkabau. ${ }^{5}$ Pendidikan Islam yang dijalankan di surau memiliki karakteristik pendidikan yang sama dengan lembaga pesantren yang dikenal di Jawa. Secara historis surau sebagai lembaga pendidikan Islam yang lengkap merupakan komplek bangunan yang terdiri dari masjid, bangunanbangunan untuk tempat belajar, dan surau-surau kecil yang menjadi pemondokan para santri yang belajar. Jika dilihat dari ukuran surau, maka dapat dibagi kedalam tiga kategori. Pertama, surau kecil yang dapat menampung sampai 20 murid. Surau ini pada umumnya digunakan sebagai tempat sholat dan belajar mengaji. Kedua, surau sedang yang dapat menampung murid sampai 80 orang. Ketiga, surau besar dapat menampung murid 100-1000 orang. Surau-surau besar biasanya berkembang karena para tuanku yang terkenal mampu menarik ratusan bahkan ribuan murid. Surau besar inilah yang memiliki pemondokan-pemondokan dan dijadikan sebagai lembaga pendidikan Islam tradisional. Sehingga surau bisa dikatakan sebagai Pesantren perspektif Minangkabau. ${ }^{6}$

Aspek penting dari surau sebagai lembaga pendidikan Islam sebagaimana juga dimiliki oleh pesantren adalah penekanan kepada pengetahuan lisan (hafalan) dengan mengkaji teks-teks klasik. ${ }^{7}$ Kombinasi Tradisi kitab kuning (klasik) dengan sentuhan nuansa sufistik menjadi ci ri khas pendidikan surau. Pendidikan surau adalah sebagai warisan tradisional Islam, dalam pengertian $\mathrm{Nars}^{8}$ adalah dunia yang mewarisi dan memelihara kontinuitas tradisi Islam yang dikembangkan dari masa ke masa, tidak terbatas pada periode tertentu dalam sejarah Islam. Tradisi yang sarat dengan pandangan dunia dan praktek Islam sebagai warisan sejarah, khususnya dalam bidang syariah dan tasawuf. Oman menambahkan bahwa peranan surau sangat signifikan sebagai tempat transmisi pengamalan tarekat sehingga tarekat bisa begitu mengakar dalam masyarakat Minangkabau, terutama terlihat pada masyarakat Ulakan dengan Tarekat Syattariyah-nya. ${ }^{9}$ Surau dan tarekat memang tidak bisa dipisahkan. Kuat dan mengakarnya tarekat dalam tradisi masyarakat Minangkabau tidak bisa terlepas dari peran surau sebagai lembaga pendidikan Islam tradisional. Semua Tarekat yang berkembang di Minangkabau mengorganisasikan dirinya melalui surau masing-masing. ${ }^{10}$

Perpaduan fiqh-sufistik yang begitu kuat mempengaruhi tradisi intelektual surau. Hal ini mengakibatkan munculnya pola pikir dan tata perilaku komunitas surau yang senantiasa berada dalam alur formulasi "normative-mistis". ${ }^{11}$ Sehingga dalam proses belajar mengajar di surau cendrung menggunakan pendekatan

${ }^{5}$ Azyumardi Azra, Surau: Pendidikan Islam Tradisional dalam Transisi dan Modernisasi ( Ciputat: Logos, 2003), 9.

6 Azra, Surau: Pendidikan Islam Tradisional dalam Transisi dan Modernisasi (Ciputat: Logos, 2003), 88.

7 Farish A Noor, Yoginder Sikand and Martin Van Bruinessen, The Madrasa Political Activism an Transnational Linkages (Amsterdam: Amsterdam University Press, 2007). Lihat juga Martin Van Bruinessen, Kitab Kuning: Books In Arabic Script Used In The Pesantren Mileu: Comments on anew collection in the KITLV Library, Bijdragen tot de TaalLand- en Volkenkunde, Deel 146, 2de/3de Afl(1990), http://www.jstor.org/stable/27864122 (Accessed: 19/05/2014 02:03).

8 Seyyed Hossein Nasr, Traditional Islam In The Modern World (London: Kegan Paul International, 1987), 11.

9 Oman Fathurahman, Jaringan Ulama: Pembaharuan dan Rekonsiliasi dalam Tradisi Intelektual Islam di Dunia Melayu-Indonesia. Studia Islamika Indonseian Journal For Islamic Studies, Vol. 11, No. 2 (2011).

${ }^{10}$ Azyumardi Azra, Surau: Pendidikan Islam Tradisional dalam Transisi dan Modernisasi ( Ciputat: Logos, 2003), 63-64.

${ }^{11}$ Mastuhu, Dinamika Sistem Pendidikan Pesantren ( Jakarta: INIS, 1994), 69. 
dogmatis. Selain itu, metode hafalan ${ }^{12}$ dengan mengutamakan ingatan santri dalam mengkaji teks-teks agama merupakan metode penting dalam tradisi intelektual pendidikan Islam tradisional. Formulasi fiqh-sufistik dalam tradisi intelektual surau ini merupakan corak keagamaan ataupun ekspresi Islam yang mengedepankan mazhab dan pengelaborasian nilai-nilai tradisi lokal.

Sebagaimana ditegaskan oleh Dhofier bahwa ekspresi Islam tradisional ketika itu bukanlah karena banyaknya elemen non Islam (baik pengaruh dari kepercayaan animism maupun Hindu-Budha), tapi keterikatan umat Islam terhadap aliran ulama-ulama yang paling berpengaruh di seluruh dunia Islam. Walaupun semakin menguatnya pengaruh gerakan puritanisasi di Timur Tengah, Islam di Minangkabau justru menguat keterikatannya kepada pikiran-pikiran Imam Syafi'l, Abu Hasan al-Asy'ari, dan Imam Juneid. Pemikiran ketiga tokoh ini telah mapan di Minangkabau sejak tahun 1200 dan tidak mudah goyah. ${ }^{13}$

Sehingga pendidikan surau merupakan lembaga pendidikan Islam yang paling diminati dan menemukan momentumnya sebelum terjadinya gerakan modernisasi oleh ulama kaum muda. ${ }^{14}$

\section{B. Surau di tengah Kontestasi Ulama Kaum Tua dan Ulama Kaum Muda}

Gelombang gerakan modernisasi Islam yang dibawa oleh murid-murid Syaikh Ahmad Khatib al-Minangkabawi yang baru kembali dari Haramayn memberikan turbulensi keagamaan yang sangat kuat. Syaikh Ahmad Khatib sendiri adalah seorang ulama kharismatik yang berasal dari Koto Gadang, berdekatan dengan Bukittinggi. Pada tahun $1876 \mathrm{M}$ ia pergi ke Mekkah untuk mendalami ilmu agama Islam, berkat kecerdasannya dan tingkat intelektualnya yang diakui sehingga Ahmad Khatib diangkat menjadi seorang Imam mazhab Syafi'l di Masjidil Haram. Ahmad Khatib adalah seorang ulama ortodok yang pemahamannya memiliki kesamaan dengan kaum Paderi dan pengkritik keras gerakan modernis Jamaluddin Al-Afghani dan Muhammad 'Abduh di Mesir.

Pada tahun 1900-an murid-murid Ahmad Khatib ini kembali ke Minangkabau menjadi ulama yang independen dan keluar dari kerangka surau tarekat. Berbeda dengan gurunya, para muridnya ini banyak terpengaruh oleh gerakan modernisasi ataupun pembaruan yang dibawa oleh 'Abduh di Mesir. Hal ini disebabkan intensitas mereka dalam membaca jurnal Urwatul Wusqa yang menjadi corong gerakan modernisasi Islam di Mesir.

Gerakan modernisasi Islam yang dimulai pada tahun 1900-an ini menjadikan ulama di Minangkabau menjadi dua faksi yang saling bergejolak. Pertama, Faksi Ulama Kaum Tua. Mereka adalah ulama tradisional yang ingin mempertahankan corak Islam sufistik melalui otoritas surau. Ulama ini seperti, Syaikh Abbas Padang Lawas, Syaikh Sulaiman Arrasuli, Syaikh Muhammad Djamil Jaho. Kedua, faksi Ulama Kaum Muda. Mereka adalah murid-murid Syaikh Ahmad Khatib Al Minangkabawi yang melakukan gerakan modernisasi di Minangkabau dengan tujuan menggugat otoritas surau dan corak Islam sufistik dan pengamalan taqlid terhadap imam mazhab. Ulama ini adalah Haji Abdullah Ahmad, Syaikh Abdul Karim Amrullah, dan Syaikh Ibrahim Musa.

12 Eric Hilgendorf, Islamic Education: History and Tendency. Peabody Journal of Education, Vol. 78, No. 2 (2003), 71, http://www.jstor.org/stable/1492943 (Accessed: 11/12/2013 22:00).

13 Zamakhsyari Dhofier, Tradisi Pesantren: Studi Pandangan Hidup Kiyai dan Visinya 280 Mengenai Masa Depan Indonesia ( Jakarta: LP3ES, 2011).

14 . Lihat, Azyumardi Azra,Jaringan Ulama timur tengah dan kepulauan Nusantara Abad XVII dan XVIII,(Jakarta: Kencana) hal 386. 
Kontestasi ulama kaum tua dan ulama kaum muda ini menimbulkan dinamika keagamaan yang sangat kuat. Hal ini menarik banyak peneliti untuk selalu mengkaji Islam di Minangkabau ini dengan berbagai pendekatannya. Schrieke, dalam membicarakan perdebatan ulama kaum tua dan ulama kaum muda di Minangkabau pada awal abad XX menyebutnya dengan istilah "pergolakan Agama". ${ }^{15}$ Pendapat Schrieke menjelaskan begitu kuatnya perdebatan keagamaan ketika itu. Hal ini tentu tidak berlebihan karena perdebatan ini menimbulkan diskursus intelektual yang sangat dinamis melalui majalah-majalah, organisasi-organisasi dan lembaga-lembaga pendidikan. Apria menganggap istilah ini terlalu berlebihan karena menurut temuannya perdebatan ulama kaum tua dan ulama kaum muda ini hanyalah dipicu oleh persoalan furu' dalam Islam. ${ }^{16}$

Munculnya pergolakan agama di awal abad $20 \mathrm{M}$ ini membuat masing-masing kelompok memperdalam hujjahnya, sehingga kitab-kitab berkembang dan diskusidiskusi sering dilakukan. Para ulama dari dua kelompok ini juga mempertahankan pendirian masing-masing dalam karya-karya yang banyak, baik berupa buku maupun majalah. ${ }^{17}$ Abdullah Ahmad, ${ }^{18}$ salah seorang ulama kaum muda menerbitkan al-Munir (1911-1916) sebagai pelanjut cita-cita pembaruan Islam di Nusantara yang dirintis oleh Syaikh Thahir Jalaluddin (1869-1959) $)^{19}$ melalui majalah al-Imam di Singapura. ${ }^{20}$ Al-Munir menjadi majalah yang lantang menyuarakan ide-ide pembaruan di Minangkabau. Percetakan Al-Munir di Padang terbakar pada tahun 1916 sehingga mengakibatkan penerbitan majalah al-Munir terhenti. ${ }^{21} \mathrm{Hal}$ ini mendorong Zainuddin Labai berinisiatif menerbitkan majalah alMunir al-Manar (1919-1924) sebagai kelanjutan majalah al-Munir. Ulama kaum tua tentu tidak mau kalah, Syaikh Muhammad Khatib Ali Padang (1861-1936) merupakan ulama dari kaum tua yang aktif dan produktif dalam menanggapi isuisu pembaruan dari ulama kaum muda. la bekerja sama dengan Datuk Sutan Maharaja untuk menerbitkan majalah Suluh Melayu dalam membendung pengaruh Al-Munir. Hamka menyebut Syaikh Khatib Ali sebagai lawan yang paling reaksioner bagi ulama kaum muda dan mempunyai pengaruh yang kuat. ${ }^{22}$

Kontestasi kaum tua dan kaum muda ini tidak hanya terbatas kepada pemahaman keagamaan. Kontestasi juga terjadi dalam pembentukan organisasi dan dalam aspek pembentukan lembaga pendidikan. Minangkabau merupakan

15 Hal ini diungkapkan Schrieke dalam artikelnya Bijdrage tot bibliografie van de hudige godsdienstige bewegin ter Sumatra 's Westkust, yang kemudian diterjemahkan kedalam bahasa Indonesia. BJO. Schrieke, Pergolakan Agama di Sumatera Barat: Sebuah Sumbangan Bibliografi (Jakarta: Bhratara, 1973).

16 Apria Putra, Naskah Catatan Haji Rasul: Dinamika Intelektual Kaum Muda Minangkabau Awal Abad XX (Tangerang Selatan: LSIP, 2014).

17 Apria Putra dan Chairullah Ahmad. Bibliografi Karya Ulama Minangkabau Awal Abad 20, Dinamika Intelektual Kaum Tua dan Kaum Muda(Padang: Komunitas Suluah, 2011), 229

18 Karel A. Steenbrink, Pesantren Madrasah Sekolah: Pendidikan Islam dalam Kurun Modern (Jakarta: LP\#3ES, 1974), 37

19 Mengenai riwayat hidupnya yang lebih lengkap, lihat Mafri Amir, Reformasi Islam Dunia Melayu-Indonesia: Studi Pemikiran, Gerakan, dan Pengaruh Syaikh Muhammad Thahir Jalaluddin 1869-1959(Jakarta: Badan Litbang dan Diklat Puslitbang Lektur Keagamaan Departemen Agama RI, 2008), 25-72. Yulizal Yunus, Syaikh Thahir Jalaluddin (1869-1950) dalam Mestika Zeid, Riwayat Hidup Ulama Sumatera Barat dan Perjuangannya, 93-110.

20 Azyumardi Azra, The Transmission of al-Manar's Reformism to the Malay-Indonesian World: The Cases of al-Imam and al-Munir, Studia Islamika Indonesia Journal for Islamic Studies, Vol. 6, No.3 (1999), 82.

${ }_{21}$ Deliar Noer, Gerakan Modern Islam di Indonesia 1900-1942(Jakarta: LP3ES, 1996), 47.

22 Hamka, Ayah ku (Jakarta: UMMINDA, 1982). 
wilayah pertama di Hindia Belanda yang menjadi tempat bagi sekolah-sekolah modern. Abdullah Ahmad dari kalangan ulama kaum muda pertama yang mendirikan sekolah modern, sekolah Adabiyah di Padang pada 1909. ${ }^{23}$ Abdullah Ahmad memang tergolong ulama inovatif dan progresif diantara ulama kaum muda lainnya. Pemikirannya yang progresif dan "melampaui zamannya" terlihat ketika ia mendirikan sekolah umum Adabiyah ini. Pendirian sekolah umum bercorak modern masih dianggap tabu di Minangkabau pada saat itu. Zarkasyi menilai usaha Abdullah Ahmad ini lebih terlihat sebagai Westernisasi daripada sebuah gerakan pembaruan. ${ }^{24}$ Munculnya anggapan ini karena hubungan Abdullah Ahmad sendiri dengan Belanda yang cukup dekat.

Pada tahun-tahun berikutnya, madrasah-madrasah yang berciri modern bermunculan di Minangkabau. Pada 1915, Sekolah Diniyah didirikan di Padang Panjang oleh Zainuddin Labai el Yunusiyah. Pada 1918, Mahmud Yunus mendirikan madrasah Diniyah di Batusangkar. Madrasah-madrasah tersebut dirancang untuk menjadi sekolah Islam modern yang mengajarkan baik mata pelajaran agama maupun umum. Metode mengajar baru diterapkan, kelas berjenjang, papan tulis, meja untuk siswa serta buku-buku.

Selain mendirikan madrasah-madrasah baru, ulama kaum muda juga mengubah surau-surau mereka dengan mengadopsi sistem pendidikan madrasah. Sebagaimana yang dilakukan oleh haji rasul dengan Surau Jembatan Besi di Padang Panjang dan Syaikh Ibrahim Musa dengan Surau Parabek. Pada tahun 1919, surau-surau ulama kaum muda yang bertransformasi menjadi madrasah ini menggabungkan diri dalam sebuah oragnisasi yang diberi nama Sumatera Thawalib. Tidak lama sesudah itu, surau-surau yang berada di Padang Japang, Maninjau dan Batusangkar ikut menggabungkan diri. Hasilnya, Sumatera Thawalib menjadi organisasi terkemuka yang didirikan oleh kaum muda di wilayah Minangkabau. selain itu, Muhammadiyah juga mendirikan sekolah-sekolah umum yang diminati di Minangkabau.

Kemajuan yang begitu pesat dalam modernisasi pendidikan Islam yang dilakukan oleh ulama kaum muda, mendorong ulama kaum tua untuk tidak tinggal diam. Ulama kaum tua harus melakukan usaha yang sama dengan ulama kaum muda dalam mempertahankan eksistensi lembaga pendidikannya. Ulama kaum tua mengawali langkah modernisasi pendidikan dengan suatu gerakan yang bermula di Candung. Pada tahun 1926, Syaikh Sulaiman Arrasuli (1871-1970) mendapat surat dari Syaikh Abbas dari Bukittinggi yang menyarankan agar bersedia mengubah sistem pengajarannya menjadi madrasah sebagaimana yang dilakukan oleh ulama kaum muda. ${ }^{25}$ Saran ini menjadi titik awal pembaruan sistem pendidikan Islam di Surau Baru Canduang yang didirikan pada tahun $1327 \mathrm{H} / 1908$ M. Sistem halaqah dirubah menjadi sistem kelas seperti di madrasah. Selain itu, madrasah ini dilengkapi dengan sarana modern seperti meja, kursi dan papan tulis. Dalam waktu singkat, langkah yang diambil oleh Syaikh Sulaiman Arrasuli diikuti oleh ulama kaum Tua lainnya yang juga memiliki lembaga Surau, seperti Syaikh A. Wahid Tabek Gadang, Syaikh Muhammad Jamil Jaho di Padang Panjang, Syaikh Arifin di Batu Hampar. ${ }^{26}$

23 Jajat Burhanuddin, Ulama dan Kekuasaan: Pergumulan Elit Muslim dalam Sejarah Indonesia ( Bandung:Mizan, 2012), 303.

${ }^{24}$ Karel A. Stenbrink, Pesantren Madrasah Sekolah: Pendidikan Islam dalam Kurun Modern (Jakarta:LP3ES, 1974), 42.

${ }^{25}$ Alaiddin Koto, Pemikiran Politik PERTI, Persatuan Tarbiyah Islamiyah 1945-1970 ( Jakarta: Nimas Multima, 1997), 35.

26 Pada 20 Mei 1930 kaum Tua mendirikan organisasi Persatuan Tarbiyah Indonesia 
Modernisasi pendidikan yang dilakukan oleh kaum tua terhadap suraunya menjadi akhir dari eksistensi surau sebagai lembaga pendidikan Islam tradisional di Minangkabau. Pola pendidikan pendidikan Islam memang seharusnya mengalami perubahan dari pola tradisional kepada pola-pola modern. ${ }^{27}$ Selanjutnya, surau hanya menjadi tempat belajar al-Qur'an, tempat sholat dan tidak ada bedanya dengan musala-musala ditempat lain.

\section{Madrasah: Model Baru Pendidikan Islam}

Indonesia telah lama akrab dengan lembaga pendidikan Islam yang disebut madrasah. Menurut Zainuddin Alavi, kata madrasah berasal dari bahasa Arab yang artinya "tempat duduk untuk belajar", yaitu tempat atau wahana untuk mengenyam proses pembelajaran secara formal dan memiliki konotasi spesifik. ${ }^{28}$ Terminologi seperti ini pada akhirnya memiliki kesamaan dengan "sekolah" dalam bahasa Indonesia. Dalam konteks Indonesia kontemporer, istilah madrasah mengacu pada sekolah-sekolah Islam tingkat dasar dan menengah yang mengadopsi sistem pendidikan modern, di mana mata pelajaran Islam diajarkan bersama pelajaran umum. ${ }^{29}$

Lembaga pendidikan Islam tradisional yang bersifat lokal semacam pondok, pesantren, dayah, dan surau seakan tidak bisa berkutik ketika berhadapan dengan gelombang modernisasi pendidikan Islam ini. Menurut Hasbullah, munculnya istilah madrasah di Indonesia dimulai sejak adanya gagasan untuk memasukkan ilmu pengetahuan umum ke dalam lembaga pendidikan Islam yang sudah menggunakan sistem klasikal pada waktu itu. ${ }^{30}$

Dalam konteks semenanjung Melayu (Malaysia), pondok juga mengalami kemunduran ketika berhadapan dengan model pendidikan barat yang diperkenalkan oleh kolonial Inggris. Sebagaimana yang dijelaskan oleh Richard bahwa pendidikan modern yang disediakan oleh Inggris menawarkan peluang besar dalam kemajuan ekonomi. ${ }^{31}$ Selain itu, bahasa Inggris yang diajarkan di sekolah modern memudahkan masyarakat untuk berinteraksi dengan kolonial inggris. Patani (Thailand Selatan) yang pada abad ke $19 \mathrm{M}$ masih menjadi pusat pendidikan Islam di Asia tenggara juga tidak bisa melepaskan diri dari modernisasi pendidikan. ${ }^{32}$ Lembaga pendidikan Islam di Patani harus berhadapan dengan kerajaan Thailand yang mengeluarkan kebijakan asimilasi kebudayaan, dimana bahasa Arab dan Melayu harus diganti dengan bahasa Thai sebagai bahasa

(PERTI) guna menyatukan aspirasi kaum Tua walaupun sistem pendidikan Surau dig anti dengan merubahnya dengan Madrasah Tarbiyah Islamiyah. Lihat Azra, Surau: Pendidikan Islam Tradisional dalam Transisi dan Modernisasi (Ciputat: Logos, 2003), 130.

${ }_{27}$ Mun'im Sirry, The Public Expression of Traditional Islam: the Pesantren and Civil Society in Post-Suharto. The Muslim World ( Jan 2010),60, (Accessed: 5/9/2014, 12:43 pm).

${ }_{28}$ Zainuddin Alavi, Muslim Educational Thought In The Middle Ages, Terj. Abuddin Nata ( Canada: Montreal, 2000), 57.

${ }^{29}$ Noorhaidi Hasan, The Salafi Madrasa of Indonesia, dalam Farish A. Noor (eds), The Madrasa In Asia: Political Activism and Transnational Linkages (Amsterdam: Amsterdam University Press, 2008).

30 Hasbullah, Kapita Selecta Pendidikan Islam ( Jakarta: Raja Grafindo Persada, 1999), 66.

${ }^{31}$ Richard G Kraince, Reforming Islamic Education In Malaysia: Doctrine Or Dialogue dalam Robert W. Hefner (ed) Making Modern Muslim, The Politic Of Islamic Education In Southeast Asia ( Honululu: University Of Hawai Press, 2009).

32 Joseph Cinyong, Islamic Education In Southearn Thailand: Negotiating Islam, Identity and Modernity dalam Robert W. Hefner (ed) Making Modern Muslim, The Politic Of Islamic Education In Southeast Asia ( Honululu: University Of Hawai Press, 2009). 
resmi. Lembaga pendidikan Islam yang tidak mau menyesuaikan diri dengan kebijakan ini pada perkembangan nya tidak mampu bertahan lama. ${ }^{33}$

Dalam konteks Minangkabau, Madrasah lahir dari "pergolakan Agama" meminjam istilahnya Schrieke antara ulama kaum tua dan ulama kaum muda. Ulama kaum tua seakan akan tidak lagi memiliki pilihan lain selain ikut melakukan modernisasi terhadap sistem pendidikan surau dan mengadopsi sistem pendidikan madrasah sebagaimana yang sudah dilakukan lebih awal oleh ulama kaum muda. Hal ini sesuai dengan apa yang dikatakan oleh Maksum bahwa latar belakang kemunculan madrasah di Indonesia setidaknya dapat dikembalikan kepada dua situasi, Pertama, adanya gerakan pembaruan Islam di Indonesia. Kedua, adanya respon pendidikan Islam terhadap kebijakan pendidikan Hindia Belanda. ${ }^{34}$ Ikhtiar yang dilakukan oleh ulama kaum tua untuk mempertahankan lembaga pendidikan tradisionalnya (surau) dengan mengadopsi sistem pendidikan madrasah menjadi awal munculnya model baru pendidikan Islam di Minangkabau.

Ulama kaum muda dan ulama kaum tua dalam waktu yang relatif singkat, tetap dengan suasana kompetitif membangun banyak madrasah sebagai alternatif modern bagi pendidikan surau. Madrasah mengadopsi sistem dan organisasi pendidikan modern yang terbukti menarik bagi banyak orang Minangkabau. Sebagaimana penjelasan Muhammad Daud Ali yang mengatakan madrasah sebagai lembaga pendidikan Islam berfungsi menghubungkan sistem lama dan sistem baru dengan jalan mempertahankan nilai-nilai lama yang masih baik serta mengambil sesuatu yang baru dalam ilmu, teknologi dan ekonomi yang bermanfaat bagi kehidupan umat Islam. ${ }^{35}$

Kurikulum madrasah pada umumnya adalah apa yang diajarkan di lembaga pendidikan Islam tradisional seperti surau ditambah dengan beberapa materi pelajaran yang disebut dengan ilmu-ilmu umum. Madrasah lahir dari semangat modernisasi pendidikan Islam pada abad 20 dengan keberhasilan umat Islam dalam mendialogkan Islam dengan modernitas dalam hal ini adalah barat.

Sistem madrasah ini, berbeda dengan surau yang berfungsi sebagai pusat pencetak ulama. Madrasah memusatkan perhatian pada penciptaan muslim terpelajar. Pada abad 20, muslim terpelajar memang muncul sebagai sebuah tipe kepemimpinan baru yang dibutuhkan masyarakat Muslim di Hindia Belanda yang mampu menguasai pengetahuan Islam maupun umum (sekuler). ${ }^{36}$

Madrasah-madrasah yang didirikan oleh ulama kaum muda di wilayah Minangkabau periode 1900-1930 adalah antara lain:

\section{1) Adabiyah School}

Sekolah ini didirikan oleh Haji Abdullah Ahmad pada tahun 1907 di Padang Panjang. ${ }^{37}$ Belum cukup satu tahun, sekolah ini gagal berkembang dan tidak diminati oleh masyarakat Padang Panjang. Hal ini disebabkan pola pendidikan yang diajarkan di sekolah ini dinilai terlalu kebaratan dan pro kolonial Hindia Belanda. Bisa jadi, pengaruh ulama kaum tua masih sangat kuat di daerah ini sehingga ide-ide pembaruan Haji Abdullah Ahmad belum mendapat tempat

28436 Jajat Burhanuddin, Ulama dan Kekuasaan: Pergumulan Elit Muslim dalam Sejarah

33 Hasan Madmarn, The Pondok and Madrasah In Patani ( Bangi: University Kebangsaan Malaysia, 2002).

34 Maksum, Madrasah: Sejarah dan Perkembangannya (Jakarta: Logos, 1999), 97.

35 Muhammad Daud Ali, Lembaga-Lemabaga Islam di Indonesia ( Jakarta: Raja Grafindo Persada, 1995), 49.

Indonesia ( Bandung: Mizan, 2012), 304.

37 Karel A Steenbrink, Pesantren Madrasah Sekolah: Pendidikan Islam dalam Kurun Modern(Jakarta:LP3ES, 1974). 
dengan baik. Sekolah ini akhirnya dipindahkan ke Padang, sambutan masyarakat cukup baik untuk perkembangan sekolah ini.

Sekolah Adabiyah adalah tipe sekolah umum yang memberikan mata pelajaran agama Islam. Pada tahu 1915, sekolah ini mendapat pengakuan dari pemerintah Belanda dan berubah menjadi Hollands Inlandsche School (HIS). ${ }^{38}$ Sekolah ini merupakan HIS pertama yang didirikan oleh organisasi Islam dan memasukkan mata pelajaran agama Islam sebagai rencana pelajarannya.

\section{2) Madrasah School (Sekolah Agama)}

Madrasah ini didirikan tahun 1910 oleh M. Thaib Umar di Sungayang, Batusangkar. Pada perkembangannya, madrasah ini tidak mampu bertahan terlalu lama. Madrasah ini terpaksa ditutup pada tahun 1913 dengan alasan kekurangan tempat. Pada tahun 1918, Mahmud Yunus mendirikan Diniyah School sebagai kelanjutan Madrasah School.

\section{3) Madrasah Diniyah}

Madrasah ini didirikan pada tanggal 10 oktober 1915 oleh Zainuddin Labay el Yunusi di Padang Panjang. Madrasah ini merupakan madrasah sore untuk pendidikan agama yang diorganisasikan berdasarkan sistem klasikal. Madrasah ini juga memberikan pendidikan umum seperti sejarah dan ilmu bumi.

\section{4) Sumatera Thawalib}

Sumatera Thawalib merupakan surau yang diubah menjadi madrasah berjenjang. Sumatera Thawalib berawal dari kelompok baca yang didirikan oleh Zainuddin Labai el-Yunusi pada 1913 dengan bantuan pelajar senior surau jembatan besi di Padang Panjang. ${ }^{39}$ Pada tahun 1916, atas prakasa seorang pelajar surau jembatan besi, Haji Habib perkumpulan ini menjadi sebuah himpunan kerja sama pelajar. Sumatera Thawalib secara formal membuka madrasah di Padang Panjang pada tahun 1921 di bawah pimpinan Haji Rasul.

Organisasi serupa juga didirikan oleh pelajar Surau Parabek di Bukittinggi. Surau terkemuka ini dibawah kepemimpinan Syaikh Ibrahim Musa, seorang ulama moderat dari kalangan ulama kaum muda Minangkabau. Kedua organisasi ini bertemu pada februari 1919 dan membentuk sebuah perserikatan yang dikenal dengan Sumatera Thawalib. ${ }^{40}$ Selanjutnya didirikan pula Sumatera Thawalib di daerah Padang Japang, Sungayang, Batusangkar dan Maninjau. Hasilnya Sumatera Thawalib tumbuh menjadi organisasi pendidikan yang terkemuka di Minangkabau.

\section{5) Madrasah Diniyah Putri}

Madrasah ini didirikan di Padang Panjang pada tahun 1923 oleh Rangkayo Rahma el-Yunusiah. Madrasah ini merupakan madrasah putri pertama di Indonesia yang bertujuan untuk memberikan kesempatan yang lebih luas kepada pelajar putri.

Adapun madrasah yang didirikan oleh ulama kaum tua pada periode 1900-1930 adalah sebagai berikut:

\section{1) Arabiyah School}

Madrasah ini didirikan pada tahun 1918 di Ladang Lawas oleh Syaikh Abbas. Awalnya Syaikh Abbas memiliki surau di daerah Alanglaweh,Bukittinggi. ${ }^{41}$ Madrasah ini adalah madrasah pertama yang didirikan oleh ulama kaum tua. Usaha Syaikh Abbas dalam mengubah suraunya menjadi madrasah pada

38 Deliar Noer, Gerakan Modern Islam di Indonesia 1900-1942 ( Jakarta: LP3ES, 1996)

39 Jajat Burhanuddin, Ulama dan Kekuasaan: Pergumulan Kaum Elit Muslim dalam Sejarah Indonesia (Bandung: Mizan, 2012), 304.

40 Deliar Noer, Gerakan Modern Islam di Indonesia 1900-1942 ( Jakarta: LP3ES, 1996).

41 Azyumardi Azra, Surau: Pendidikan Islam Tradisional Dalam Transisi dan Modernisasi ( Ciputat: Logos, 2003), 129. 
awalnya mendapatkan perlawanan dari kolega-koleganya sesama ulama kaum tua. Namun perlahan-lahan usaha ini diikuti oleh ulama kaum tua yang lain. Pada tahun 1924 Syaikh Abbas juga membuka madrasah lain di Bukittinggi.

\section{2) Madrasah Tarbiyah Islamiyah}

Madrasah Tarbiyah Islamiyah (MTI) merupakan surau-surau ulama kaum tua yang mengalami modernisasi menjadi madrasah. Pada tahun 1926, Syaikh Sulaiman Arrasuli (1871-1970) mendapat surat dari Syaikh Abbas dari Bukittinggi yang menyarankan agar bersedia mengubah sistem pengajarannya menjadi madrasah sebagaimana yang dilakukan oleh ulama kaum muda. ${ }^{42}$ Saran ini menjadi titik awal pembaruan sistem pendidikan Islam di Surau Baru Canduang yang didirikan pada tahun $1327 \mathrm{H} / 1908 \mathrm{M}$. Sistem halaqah diubah menjadi sistem kelas seperti di madrasah. Selain itu, madrasah ini dilengkapi dengan sarana modern seperti meja, kursi, dan papan tulis.

Ulama kaum tua lainnya yang juga memiliki lembaga surau pada akhirnya mengikuti langkah yang diambil oleh Syaikh Sulaiman Arrasuli diikuti oleh, seperti yang dilakukan oleh Syaikh A. Wahid Tabek Gadang , Syaikh Muhammad Jamil Jaho di Padang Panjang, dan Syaikh Arifin di Batu Hampar. ${ }^{43}$ Seluruh madrasah yang didirikan oleh para ulama kaum tua ini kemudian diberi nama Madrasah Tarbiyah Islamiyah dan tergabung dalam organisasi bernama Persatuan Tarbiyah Islamiyah (PERTI).

Kemunculan gelombang madrasah ini sebagaimana di tulis oleh Jajat menunjukkan serangan serius terhadap otoritas ulama tradisional. ${ }^{44}$ Tidak hanya dengan metode dan bahan pengajaran baru yang mulai diperkenalkan di madrasah, tetapi juga dengan menciptakan elite agama baru selain ulama tradisional. Madrasah dikemudian hari sangat berperan dalam membentuk masyarakat muslim baru Minangkabau yang mampu mendialogkan antara Islam, Adat dan Modernitas dengan sangat Baik.

\section{Kesimpulan}

Surau merupakan lembaga adat Minangkabau yang mengalami Islamisasi. Fenomena ini memiliki kesamaan dengan lembaga tradisional lain seperti pesantren, dayah, pondok dan meneusah. Surau menjadi lembaga pendidikan Islam tradisional di Minangkabau diawali oleh Syaikh Burhanuddin yang membangun suraunya di daerah Ulakan Pariaman sebagai pusat transmisi Tarekat Syattariah. Surau memang memiliki hubungan yang tidak dapat dipisahkan dari tarekat, sehingga corak pendidikan Islam di surau sangat kental tradisi dan nuansa sufistiknya.

Surau menjadi primadona pendidikan Islam di Minangkabau sampai munculnya gerakan pembaruan Islam di Minangkabau pada awal abad ke 20. Ulama-ulama yang dididik dengan tradisi surau menuntut ilmu ke Timur Tengah, tepatnya kepada Syaikh Ahmad Khatib al-Minangkabawi. Di Timur Tengah ini lah mereka berinteraksi dengan gerakan pembaruan Islam Muhammad Abduh. Ulama yang terpengaruh oleh gerakan pembaruan Islam ini disebut dengan ulama kaum muda. Ketika pulang ke Minangkabau, ulama kaum muda ini mulai melakukan gerakan pembaruan terutama terhadap model pendidikan Islam di Minangkabau. Ulama

\footnotetext{
42 Alaiddin Koto, Pemikiran Politik PERTI, Persatuan Tarbiyah Islamiyah 1945-1970 ( Jakarta: Nimas Multima, 1997), 35.

${ }^{43}$ Azyumardi Azra, Surau: Pendidikan Islam Tradisional dalam Transisi dan Modernisasi (Ciputat: Logos, 2003), 130.

44 Jajat Burhanuddin, Ulama dan Kekuasaan: Pergumulan Elit Muslim dalam Sejarah Indonesia ( Bandung: Mizan, 2012), 305.
} 
kaum muda mulai mengkritik otoritas surau dan menawarkan modernisasi pendidikan dengan mendirikan Madrasah.

Madrasah menjadi model baru pendidikan Islam di Minangkabau menggantikan surau. Pola pendidikan madrasah ini pada perkembangannya lebih diminati oleh masyarakat Minangkabau dan juga kolonial belanda karena model pendidikan ini yang lebih modern. Madrasah juga berperan penting dalam membentuk masyarakat muslim baru di Minangkabau yang lebih dinamis dalam mendialogkan Islam, adat, dan modernitas.

\section{Daftar Pustaka}

Alavi, Zainuddin. Muslim Educational Thought In The Middle Ages, Terj. Abuddin Nata. Canada: Montreal, 2000.

Azra, Azyumardi. Jaringan Ulama timur tengah dan kepulauan Nusantara Abad XVII dan XVIII. Jakarta: Kencana, 2013.

Azra, Azyumardi. Surau: Pendidikan Islam Tradisional dalam Transisi dan Modernisasi. Ciputat: Logos, 2003.

Azra, Azyumardi. The Transmission of al-Manar's Reformism to the MalayIndonesian World: The Cases of al-Imam and al-Munir, Studia Islamika Indonesia Journal for Islamic Studies, Vol. 6, No.3 (1999).

Burhanuddin, Jajat. Ulama dan Kekuasaan: Pergumulan Elit Muslim dalam Sejarah Indonesia. Bandung:Mizan, 2012.

Dhofier, Zamakhsyari. Tradisi Pesantren: Studi Pandangan Hidup Kiyai dan Vsinya Mengenai Masa Depan Indonesia. Jakarta: LP3ES, 2011.

Fathurahman, Oman. Jaringan Ulama: Pembaharuan dan Rekonsiliasi dalam Tradisi Intelektual Islam di Dunia Melayu-Indonesia. Studia Islamika Indonseian Journal For Islamic Studies, Vol. 11, No. 2 (2011).

Hamka, Ayah ku. Jakarta: UMMINDA, 1982.

Hasan, Noorhaidi. The Salafi Madrasa of Indonesia, dalam Farish A. Noor (eds), The Madrasa In Asia: Political Activism and Transnational Linkages. Amsterdam: Amsterdam University Press, 2008.

Hefner, Robert W. (edit), The New Cambridge History of Islam, vol 6: Muslims and Modernity Culture and Society since 1800. London: Cambridge University Press, 2011.

Hefner, Robert W.(ed) Making Modern Muslim, The Politic Of Islamic Education In Southeast Asia. Honululu: University Of Hawai Press, 2009.

Herrera, Linda. Education, Islam, and Modernity: Beyond Westernization and Centralization. Comparative Education Review, Vol. 48, No. 3 (August 2004), pp. 318-326. Accessed: 11/12/2013 21:59

Hilgendorf, Eric. Islamic Education: History and Tendency. Peabody Journal of Education, Vol. 78, No. 2 (2003), 71, http://www.jstor.org/stable/1492943 (Accessed: 11/12/2013 22:00).

Karel A. Stenbrink. Pesantren Madrasah Sekolah: Pendidikan Islam dalam Kurun Modern. Jakarta:LP3ES, 1974.

Koto, Alaiddin. Pemikiran Politik PERTI, Persatuan Tarbiyah Islamiyah 1945-1970. Jakarta: Nimas Multima, 1997.

Madmam, Hasan. The Pondok and Madrasah in Patani. Bangi: Penerbit Universiti Kebangsaan Malaysia, 1999.

Mafri Amir, Reformasi Islam Dunia Melayu-Indonesia: Studi Pemikiran, Gerakan, dan Pengaruh Syaikh Muhammad Thahir Jalaluddin 1869-1959. Jakarta: 
Badan Litbang dan Diklat Puslitbang Lektur Keagamaan Departemen Agama RI, 2008.

Mastuhu, Dinamika Sistem Pendidikan Pesantren. Jakarta: INIS, 1994.

Nars, Seyyed Hossein. Traditional Islam In The Modern World. London: Kegan Paul International, 1987.

Noer, Deliar. Gerakan Modern Islam di Indonesia 1900-1942. Jakarta: LP3ES, 1996.

Noor, Farish A, Yoginder Sikand and Martin Van Bruinessen, The Madrasa Political Activism an Transnational Linkages. Amsterdam: Amsterdam University Press, 2007.

Putra, Apria dan Chairullah Ahmad. Bibliografi Karya Ulama Minangkabau Awal Abad 20, Dinamika Intelektual Kaum Tua dan Kaum Muda. Padang: Komunitas Suluah, 2011.

Putra, Apria. Naskah Catatan Haji Rasul: Dinamika Intelektual Kaum Muda Minangkabau Awal Abad XX. Tangerang Selatan: LSIP, 2014.

Sirry, Mun'im. The Public Expression of Traditional Islam: the Pesantren and Civil Society in Post-Suharto. The Muslim World ( Jan 2010),60, (Accessed: 5/9/2014, 12:43 pm). 